Article

\title{
Effect of Impeller Design on Power Characteristics and Newtonian Fluids Mixing Efficiency in a Mechanically Agitated Vessel at Low Reynolds Numbers
}

\author{
Marek Jaszczur ${ }^{1, *(\mathbb{D}}$, Anna Młynarczykowska ${ }^{2}$ and Luana Demurtas ${ }^{3}$ \\ 1 Faculty of Energy and Fuels, AGH University of Science and Technology, 30059 Krakow, Poland \\ 2 Faculty Mining and Geoengineering, AGH University of Science and Technology, 30059 Krakow, Poland; \\ mindziu@agh.edu.pl \\ 3 Department of Ingegneria Civile, Ambientale e Architettura, University of Cagliari, 09123 Calgari, Italy; \\ luana.demurtas@gmail.com \\ * Correspondence: jaszczur@agh.edu.pl; Tel.: +48-12-6172657
}

Received: 30 November 2019; Accepted: 29 January 2020; Published: 3 February 2020

\begin{abstract}
The mixing process is a widespread phenomenon, which plays an essential role among a large number of industrial processes. The effectiveness of mixing depends on the state of mixed phases, temperature, viscosity and density of liquids, mutual solubility of mixed fluids, type of stirrer, and, what is the most critical property, the shape of the impeller. In the present research, the objective was to investigate the Newtonian fluids flow motion as well as all essential parameters for the mechanically agitated vessel with a new impeller type. The velocity field, the power number, and the pumping capacity values were determined using computer simulation and experimental measurements. The basis for the assessment of the intensity degree and the efficiency of mixing had to do with the analysis of the distribution of velocity vectors and the power number. An experimental and numerical study was carried out for various stirred process parameters and for fluids whose viscosity ranged from low to very high in order to determine optimal conditions for the mixing process.
\end{abstract}

Keywords: fluid mixing; agitated vessel; stirred tank; impeller

\section{Introduction}

Stirred vessels are widely used in a large number of chemical and engineering processes. They also play an essential role in the food industry, bioprocessing, wastewater treatment, and mineral processing to accomplish homogenization, heat transfer, gas dispersion, solid suspension, etc. [1]. They play an important role in selected processes as prevention of sediment aggregation, gas dispersion in liquids, the formation of suspensions and slow-sedimenting mixtures. In the number of analyses, researchers achieved a certain degree of awareness on the basic development and mechanism of fluid mixing, above all, on the single-phase flow. Nevertheless, there is still insufficient information on the fluid behavior particularly in unbaffled single-impeller stirred vessels which are highly important in the pharmaceutical and cosmetics industry, which require the highest standard of cleanliness, or in shear-sensitive cultures that need an appropriate gas intake [2].

Independent of an industrial process, the main goal has always been to find the most efficient and nondestructive method of mixing which consumes as low amounts of power as possible. For that reason, a large number of research studies have been performed to obtain various shapes for the impellers that could achieve a high-quality mixture usually with low axial velocity, low shear stress, and low internal heat generation, which are crucial issues for vitamins, enzymes, and for food production. Undeniably, 
substantial progress has been made in reference to energy consumption by the mixing systems that can be still minimized by modifying the shape of the single impeller. That becomes particularly important nowadays when energy consumption and environmental care become a critical issue and may determine the economic success of the investment. In multi-impeller systems, one recently preferred which utilizes a single impeller, the shape is also a crucial issue because it consists of a series of single impellers. The shape of the single impeller is a primary issue on the basis that more advanced systems can be developed.

In a research study performed by T. Su et al. [3] the power consumption, the fluid phenomenon, hydrodynamics of the flow, and the mixing process using the Rushton-type impellers were compared. The analyses showed an $18 \%$ decrease in power owing to the modification of the Rushton turbine shape, which also managed to enhance the local fluid velocity and obtain higher turbulence intensity around the optimized impeller.

F. Scargiali et al. [4] analyzed the impact of the Reynolds and Froude numbers on the power consumption characteristics in the case of unbaffled stirred tanks. The authors concluded that the primary factor that impacts power consumption and the mixing intensity is the shape of the impeller. Hence, many analyses have been performed in order to find the optimal shape of the impellers suitable for a wide range of processes. T. Kumaresan and J.B. Joshi [5] investigated the impact of impeller geometry on the fluid flow pattern and mixing time for preselected sets of axial impellers (pitched blade turbines and hydrofoils). The authors observed that the shape with a blade twist decreased the power number and flow numbers and that, for a down-flow impeller, the jet stream leaving the impeller strongly interacted with the stirred vessel and generated high-energy dissipation below the impeller. On the other hand for the up-flow impeller, the jet stream leaving the impeller interacted with the free surface and generated significantly lower energy dissipation.

In another work, M. Basavarajappa et al. [6] analyzed turbulent fluid flow characteristics in laboratory-scale stirred vessels characterized by different geometries using Computational Fluid Dynamics (CFD) simulations and comparing the Rushton turbine with the flotation impeller.

H. Ameur et al. [7] performed a three-dimensional numerical analysis to investigate the effects of blade diameter and blade curvature as well as the blade number and Reynolds number on power consumption. The authors concluded that the curvature of the blades had the most significant impact on power reduction and the efficiency of the mixing process. The energy consumption for an agitated vessel equipped with a pitched blade turbine and the performance impellers was the object of a detailed study in $[8,9]$. Due to their high-efficiency, the most high-speed turbine-type impellers are often used in industrial processes. Such a solution produces a radial-axial or radial-fluid motion. One of the well-known constructions is a Rushton turbine. However, due to the hopper formation for high rotational speed, quite often two to four baffles need to be used, which separate stirring areas. The stirred vessel geometry and the turbine shape and position of the blades or the number of turbines have been found to play an essential role in energy consumption and mixing intensity [10].

In the literature, only a small number of numerical and experimental studies deal with laminar mixing as a promising alternative to the more destructive turbulent mixing which also consumes more power [11]. For this type of flow regime, energy consumption can also be significantly decreased by modifying the shape of the impeller. In different studies, Ferrari and Rossi [12] and Rossi et al. [13] analyzed the mixing performance in a quasi-turbulent flow via the measurements of power input and output in the fluid. In the past, a mechanically agitated vessel design was limited to the mere empirical experiment, as a result of a deficiency reliable computational fluid dynamics models and the inadequacy of computer resources. At present, computer technology and advanced single-phase, multi-phase, or dispersion-phase models enable researchers to rely in the majority of cases on a numerical analysis in order to predict the hydrodynamics of more and more complex systems, replacing at the same time the number of the time-consuming and expensive experiments during the prototyping phase. On the other hand, due to the continuous increase in the complexity of the flow phenomenon, an experimental analysis is still required [14] as the final step of the analysis or of the optimization process. 
Many researchers have made assessments of different turbulent models to the study mixing phenomena in stirred vessels. A. Delafosse et al. [15] performed a research study in the flow behavior during mixing between two adjacent compartments using CFD modelling. The results showed that the numerical model was capable of reproducing with reasonable accuracy the spatial distribution of concentrations during the mixing process, without any adjustable parameters. The analyses presented by $\mathrm{H}$. Singh et al. [16] compared different turbulence models, including $k-\varepsilon$, exhibiting the accuracy of prediction for the mean axial and tangential velocities. Results obtained close to the impeller were very accurate but the numerical solution failed to predict the decay of the mean radial velocity away from the impeller. The authors noticed that the $k-\varepsilon$ model predicted the random and periodic components of the kinetic energy of fluctuating motion poorly in the vicinity of the impeller. The $k-\varepsilon$ model has also been compared to the RSTM (Reynolds Stress Turbulent Model) and LES (Large Eddy Simulation) in the work of B.N. Murthy et al. [17]. They found that the standard $k-\varepsilon$ model under predicted the turbulent kinetic energy profile in the impeller region and failed to simulate the mean flow associated with the strong swirl.

Current research studies have indicated the advantageous characteristics of stirred vessels with more than one impeller. Recent analyses have shown that the use of systems with many impellers can solve many technical mixing-related problems. Multiple-impeller systems require less energy per volume [18]. The typical stirred vessels with a single-impeller are often criticized because they generate non-uniform shear distribution, which is recognized as harmful, especially for the pharmaceutical and the cosmetics industry. The flow field in multiple-impeller systems is similar to that generated by the single-impeller systems, only when the distance between the impellers is larger than the diameter of the impeller. The required power of systems with multiple impellers is also dependent on the impeller clearance and for the distance of the impellers which is greater than one impeller diameter, the required power can be evaluated by a superposition of individual solutions [19]. However, for shorter distances, the power consumption is much smaller about $30-50 \%$ in reference to superposition. In [20] authors investigated the flow field and the power consumption in reference to the coaxial impeller (a double inner mixer with four-pitched-blade turbine and a Rushton turbine) in transitional to laminar flow regimes. The results show that the outer frame had a very small impact on the required power while the inner impeller behaved differently and had a large influence on the power required by the outer frame. In reference to the single rotation mode, the outer frame required a significant increase of power in the counter-rotation mode and a decrease of power in the co-rotation mode. The authors conclude that the co-rotation mode should be preferred because it generated a similar flow field but required much lower power.

An interesting investigation of the mixing intensification with two coaxial mixers including an anchor was conducted in [21]. The mixing quality obtained for various configurations was assessed for the transitional to laminar flow regime in the co-rotating mode using experimental measurement and a computational fluid dynamic. The authors evaluated the functional correlation for the mixing efficiency in reference to complex configurations.

Scale-up in laminar to transient flow regimes in the case of multi-impeller system has been conducted in [22]. A unique methodology of scale-up applied in reference to an industrial mixing vessel was proposed. One presented an approach that can be very helpful in reference to the process of scaling in situations when the hydrodynamic becomes essential. In review paper [23], the authors showed that the current analyses concentrated on the effect of the multiple-impeller combinations on the required power, mixing time, flow pattern, and mass transfer but there was still a need for future research on multiple-impeller systems in the aspects related to the different impellers geometries, numerical studies on the power and flow field, or studies on solid suspensions. In [24], the authors analyzed horizontal velocity fields in stirred vessels with helical coils using the particle image velocimetry method. They found that the flow pattern generated by the Rushton turbine was dominated by tangential flow structures and the cross-flow structures through cylindrical coils were not observed. The influence of various internal heat exchanger (heating plugs, helical pipe coils, pipe 
registers) and stirred tank bottom geometries (flat, torispherical, hemispherical) on the velocity field and the kinetic energy of turbulence in agitated vessels were investigated [25] using stereo-Particle Image Velocimetry (PIV) experimental measurements. The research studies show advantages as well as disadvantages of various setup configurations which have a significant impact on the fluid flow and heat transport.

The investigation of potentials in efficiency optimization for stirred vessels in laboratory-scale configuration is presented in [26]. The model was analyzed using PIV and LIF (laser-induced fluorescence) methods which give a good validation basis for CFD.

In a large number of investigations, a particular effort was made in reference to the impeller geometry as well as the vessel shape. As a result, several new types for the impeller design and the vessel were proposed in the past. Astonishingly enough, the unbaffled vessel regarded in the past as less effective in reference to the baffled one recently turned out to be more effective. A new investigation has shown that unbaffled vessel but one equipped with an appropriately designed impeller can be an excellent alternative to the baffled vessel [27-29]. Recent analyses estimated that optimized impeller-vessel configuration without baffles for a complete mixture homogenization requires significantly lower energy $[1,30]$. This demonstrates the significant and unexplored potential of unbaffled vessels. Besides that, vessels with baffles are not recommended in applications where substantially a shear can significantly affect the quality of the product, for example, in reference to the production of drugs, creams, vitamins, and enzymes [31]. For that application, proper impeller design is a critical issue. In the literature, there is neither sufficient information on the optimal impeller design, particularly for unbaffled vessels, nor information concerning fluid phenomena in such vessels. However, for every industrial process the main goal is to find a nondestructive way of mixing which properly homogenizes the product, maintaining high product quality and using as low amounts of electrical power as possible.

Thus, there is still a need for more research studies on the applications of impeller systems and on new novel geometries which ensures high-quality and effective mixing. Depending on what the mixing process has to carry out, it is appropriate to select different geometrical configurations. That is particularly crucial for unbaffled vessels, a solution which has been recommended recently for many applications. However, at present, there is a poor choice of impellers suitable for unbaffled vessels or various situations as well as operating conditions. In order to save time, materials, and environment, companies (pharmaceutical, chemical, and cosmetics) are interested in liquids mixing directly in tanks where liquids are transported. They search for impeller type to be suitable to (cylindrical and rectangular) vessels with a flat bottom and no baffles. For this reason, the present studies aimed to propose and analyze a novel impeller shape that has good efficiency and low power consumption for wide viscosity ranges. The developed impellers are suitable for a large variety of emulsions which are able to yield high-quality products. The present paper focused on mixing efficiency using the power number, capacity number, mean axial velocity, and mean radial velocity. An effect of impeller design on power characteristics and mixing efficiency for the Newtonian fluids at the low Reynolds number conditions in a mechanically agitated vessel was analyzed using the computational fluid dynamic and experimental measurement.

\section{The Experimental Setup and Methodology}

The mechanically agitated vessel configuration is presented in Figure 1, and the dimensions that were used are shown in Table 1. As a working fluid in experimental and numerical analysis depending on the case, $100 \%$ glycerol ( $\left.\rho=1261.1 \mathrm{~kg} / \mathrm{m}^{3}, \mu=1.4101 \mathrm{~Pa} \cdot \mathrm{s}\right), 30 \%$ propylene glycol solution, and distilled water were used at the temperature $20^{\circ} \mathrm{C}\left(+/-0.2^{\circ} \mathrm{C}\right)$. The distance between the impeller and the bottom of the stirred vessel $h$ was, in this case, a dependent parameter and was equal to $\frac{1}{4} H$, $1 / 3, H, \frac{1}{2} H$, and $2 / 3 H$ of the fluid initial high $H$. 


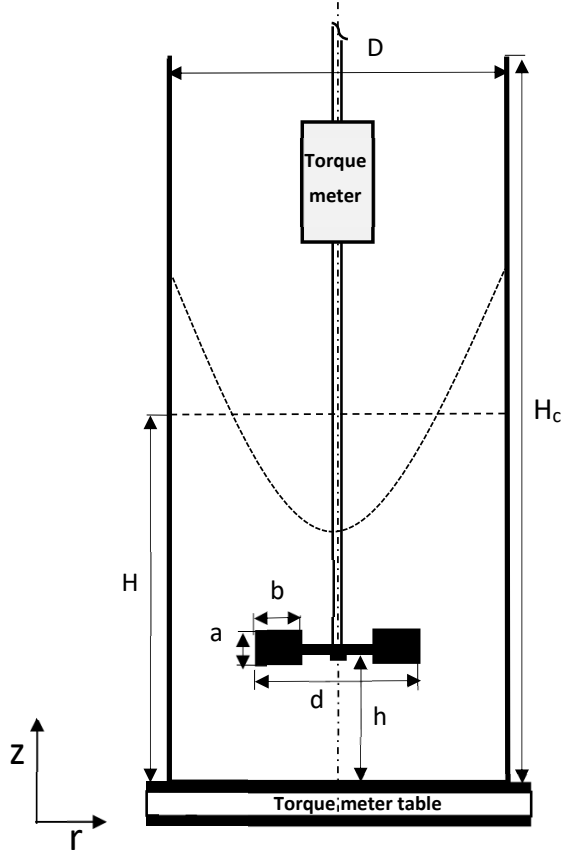

(a)

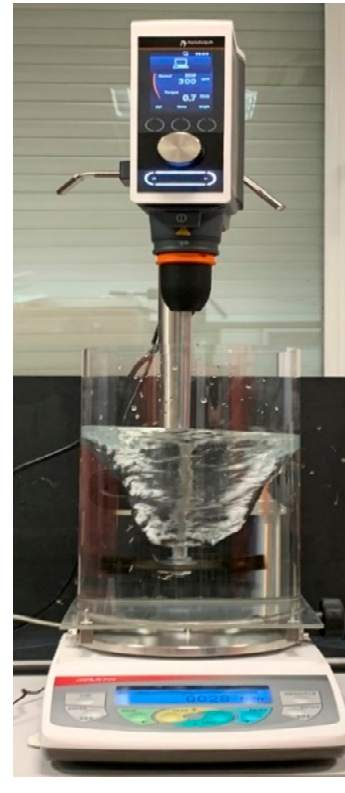

(b)

Figure 1. Schematic diagram of the experimental setup with a Rushton turbine and an agitated vessel (a) and a photo of the experimental setup (b).

Table 1. Dimensions of the stirred tank and the Rushton turbine.

\begin{tabular}{ccccccc}
\hline Symbol & $\begin{array}{c}\boldsymbol{H}, \boldsymbol{H}_{\boldsymbol{c}} \\
\mathbf{m m}\end{array}$ & $\begin{array}{c}\boldsymbol{h} \\
\mathbf{m m}\end{array}$ & $\begin{array}{c}\boldsymbol{D}, \boldsymbol{d} \\
\mathbf{m m}\end{array}$ & $\begin{array}{c}\boldsymbol{a} \\
\mathbf{m m}\end{array}$ & $\begin{array}{c}\boldsymbol{b} \\
\mathbf{m m}\end{array}$ & $\begin{array}{c}\boldsymbol{c} \\
\mathbf{m m}\end{array}$ \\
\hline \multirow{2}{*}{ Dimension } & 170,300 & $\begin{array}{c}\frac{1}{4} H, 1 / 3, \mathrm{H}, \frac{1}{2} H_{,}^{2} / 3 H \\
42,57,85,113\end{array}$ & $\begin{array}{c}170 \\
85\end{array}$ & 12 & 15 & 2 \\
\hline
\end{tabular}

The $H$ denotes the fluid level while $H_{c}$ is the total tank height and $D$ is the tank diameter. The impeller diameter is denoted as $d$. Additional geometrical dimensions are $a, b, c$, height, width, and thickness for Rushton turbine blades and $a$ and $b$ are height and width of the Novel-1 impeller cross-section and $d_{1}$ and $d_{2}$ refer to the diameter at the entrance and exit to the Novel-0 impeller while $l$ is the impeller length (see Figure 2 and Table 2 for dimensions).

The stirred tank that was studied had smooth walls and no baffled pilots. The impeller was equipped with a six-bladed Rushton turbine (for case A) or with the three arms novel impellers (for cases B and C). The Novel impellers were a rescaled copy of the real impeller developed by the authors for the industry. The analyzed scale-down impellers were created using a 3D printer and had smooth plastic walls whose thickness was $2.0 \mathrm{~mm}$.

The stirred tank was installed on the specially designed table equipped with calibrated torque meter FSA-2 (AXIS, max $2 \mathrm{~N} \cdot \mathrm{m}$ ) enabling the measurement of the vessel caused by the analyzed impeller torque with the precision of $0.001 \mathrm{~N} \cdot \mathrm{m}$ and the sampling frequency of $1000 \mathrm{~Hz}$. An additional torque meter (with the precision of $0.002 \mathrm{~N} \cdot \mathrm{m}$ ) was installed in a fully controlled Hei-TORQUE Precision 100 electrical motor with a digital overhead stirrer. A monitoring system ensured a consistent rotational speed independent of instantaneous fluid viscosity and the impeller shape during measurements.

To evaluate the mixing properties, the velocity field, as well as the pumping capacity, the particle image velocimetry (PIV) method, was used. In order to minimize optical distortion during PIV measurement, a cylindrical stirred vessel (made of 4-mm-thick plexiglass) was installed inside the square vessels (made of 3-mm-thick high-quality glass) filled with water. This successfully reduced 
the unwanted distortion in the experiments and ensured after conducting 2D calibration procedure high-quality seed double-images for post-processing.
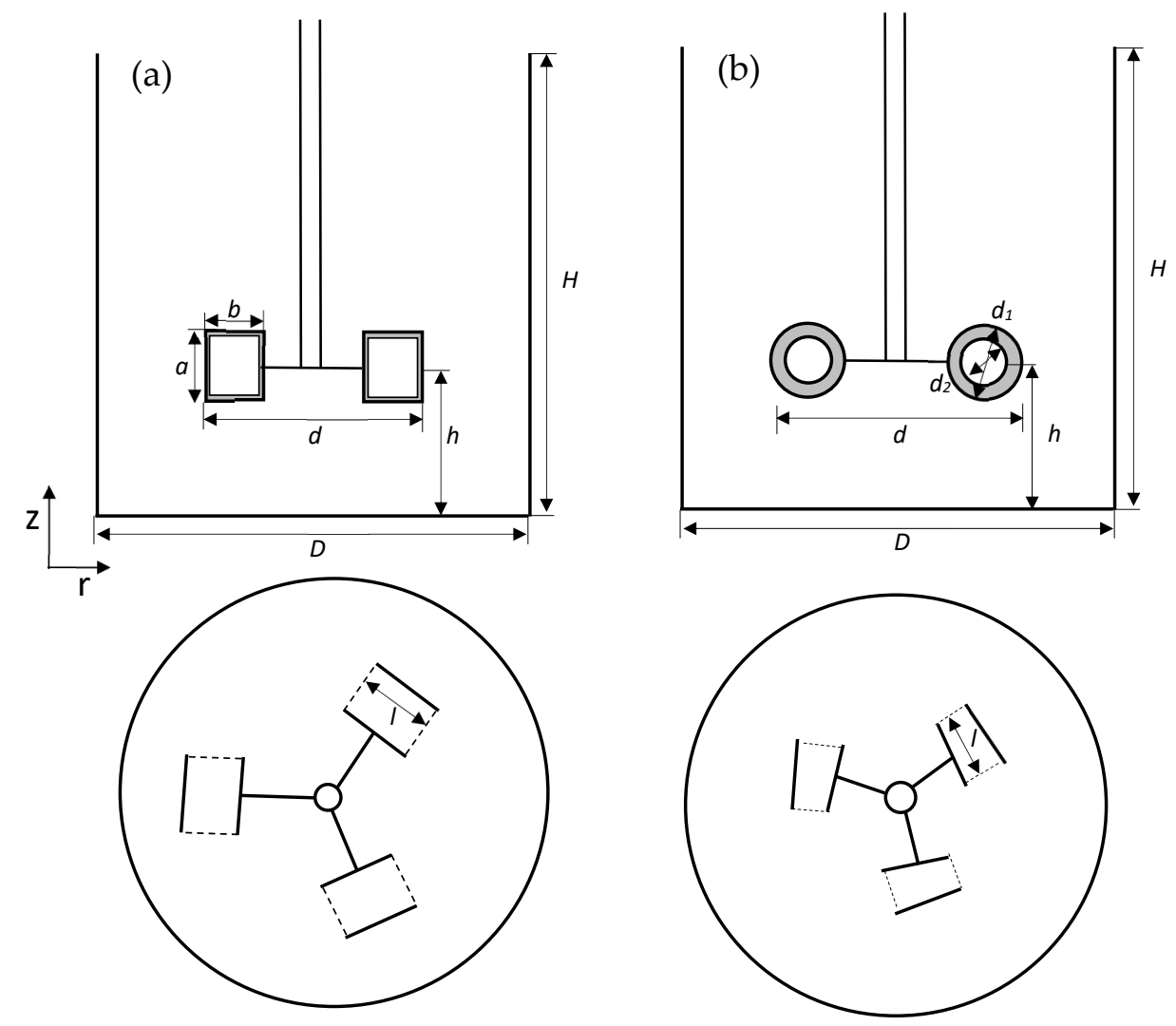

Figure 2. The geometry of stirred tank with (a) Novel-1 impeller (squire type) and (b) Novel-0 impeller (round type). The top figure is the side view and the bottom one is the top view.

Table 2. Dimensions of the stirred tank and Novel impellers.

\begin{tabular}{|c|c|c|c|c|c|c|}
\hline Impeller Type & $\begin{array}{l}H, D \\
\mathrm{~mm}\end{array}$ & $\begin{array}{c}h \\
\mathrm{~mm}\end{array}$ & $\begin{array}{c}d \\
\mathrm{~mm}\end{array}$ & $\begin{array}{l}a / d_{1} \\
\mathrm{~mm}\end{array}$ & $\begin{array}{l}\mathrm{b} / d_{2} \\
\mathrm{~mm}\end{array}$ & $\begin{array}{c}\mathrm{l} \\
\mathrm{mm}\end{array}$ \\
\hline Novel-1 & \multirow{2}{*}{$\begin{array}{l}220 \\
220\end{array}$} & \multirow{2}{*}{$\frac{80}{\frac{1}{4} H, 1 / 3 H, \frac{1}{2} H, 2 / 3 H}$} & \multirow{2}{*}{$\begin{array}{c}130 \\
85\end{array}$} & 40 & 30 & 38 \\
\hline Novel-0 & & & & 15 & 18 & 40 \\
\hline
\end{tabular}

The instantaneous velocity in the axial and radial directions were measured in the tank (filled under no agitation conditions) with a fluid at high $H=D$ (in total about $5 \mathrm{~L}$ ). It should be noticed that, due to the rotation, fluid level close to the cylinder wall increased. However, all the experiments whose results are presented in this work were conducted for a subcritical flow regime to avoid air sucking from the area above the free surface. As shown in the literature, a large number of even small air bubbles may significantly influence PIV measurement as well as fluid properties.

The seed particles (the diameter of glass hollow spheres was below $1 \mu \mathrm{m}, \rho=1020 \mathrm{~kg} / \mathrm{m}^{3}$ ) were illuminated with a double-pulse Nd: YAG laser of the energy of about $30 \mathrm{~mJ}$ per pulse. A vertical laser sheet (height, $200 \mathrm{~mm}$; thickness, about $1 \mathrm{~mm}$ ) was located in the center of the vessel directly illuminating the rotor shaft and completely shadowing the left-hand part of the tank. At present configuration, one CCD camera (La Vision) with a resolution of $2048 \times 2048$ pixels equipped with a $50-\mathrm{mm} / 1.2$ lens was used. Laser light reflected from seed particles was acquired by the CCD camera, installed perpendicularly to the plane of the light sheet. To determine the distribution of the velocity vectors, seed particles were registered by the CCD camera on two different and consecutive frames. 
The measuring PIV system was subjected to testing and calibration procedures under fluid flow condition in order to evaluate the minimum number of acquired images required to ensure accurate statistics, as well as the optimal size of the interrogation window for the cross-correlation application. In each measurement, 100 frames were acquired with the CCD camera at a frequency of $5 \mathrm{~Hz}$, which yielded the duration of a single measurement equal to $20 \mathrm{~s}$. This duration and the number of frames were sufficient for an analysis at a low Reynolds number $(R e=10-1000)$ presented here. The time step $\Delta t$ between double frames varied depending on Reynolds number ranging from 500 up to 20,000 $\mu$ s.

During the calculations, the interrogation windows size that exhibited satisfying results varied from $32 \times 32$ pixels to $64 \times 64$ pixels and with an overlapping $25 \%$. To analyze the time series of frames and to evaluate the velocity vector components, the Davis software ver. 8.0 with PIV/LIF module was used.

In the mixing system analysis, there were two important criteria numbers: Power number $N_{p}$ and Reynolds number Re defined and calculated according to the following equations:

$$
N_{P}=\frac{P}{\rho N^{3} d^{5}} \quad ; \quad R e=\frac{N d^{2} \rho}{\mu}
$$

where $\rho$ is the density $\left(\mathrm{kg} / \mathrm{m}^{3}\right), \mu$ is the viscosity $(\mathrm{kg} / \mathrm{m} \cdot \mathrm{s}), N$ is the number of rotations per second (rot $\left./ \mathrm{s}\right)$, $d$ is the maximum diameter of the impeller rotor $(\mathrm{m})$, and $P$ is the power $(\mathrm{W})$ required to rotate the impeller with a specific rotational speed. It depends on the torque $\tau$, and can be evaluated as follows:

$$
P=2 \pi \cdot N \cdot \tau
$$

where $\tau$ is the torque $(\mathrm{N} \cdot \mathrm{m})$.

The third important parameter is the pumping capacity $Q$. It can be calculated for different Reynolds numbers through a cylindrical (vertical) surface with a specified radius $r$ or through the horizontal surface at heights $z$. In the present configuration, the pumping capacity was evaluated through a horizontal surface (axial pumping capacity $Q_{z}$ ) and for the height $z=0.01 \mathrm{~m}$. Axial pumping capacity $Q_{z}$ can be obtained from PIV measurement by integrating the mean axial velocity over the whole horizontal positions, i.e., from $r_{1}=0 \mathrm{~m}$ to $r_{2}=0.085 \mathrm{~m}$.

$$
Q_{z}=\int_{r_{1}}^{r_{2}}\left|u_{z}\right| d S
$$

It is also common to normalize this parameter with rotational speed and the impeller diameter, i.e., $N \cdot d^{3}$ yielding one of the global flow characteristics.

\section{Numerical Modelling}

The mechanically agitated vessel configuration is presented in Figure 2a,b, and the dimensions used are shown in Table 2. For presented results, water was used as a working fluid with a viscosity at a selected temperature. For numerical analyses, the distance between the impeller and the bottom of the tank $h$ was equal to $80 \mathrm{~mm}$.

The steady state of flow behavior inside the stirred tank can be described by governing equations for mass and momentum conservation. The continuity equation, for a 3D analysis, is as follows:

$$
\frac{\partial u_{1}}{\partial x_{i}}+\frac{\partial u_{2}}{\partial x_{j}}+\frac{\partial u_{3}}{\partial x_{k}}=0
$$

For momentum conservation, assuming incompressible fluid, the Navier-Stokes equations are given by:

$$
\rho \frac{D u_{i}}{D t}=\frac{\partial u_{i}}{\partial x}+\mu\left(\frac{\partial^{2} u_{i}}{\partial x_{i}^{2}}+\frac{\partial^{2} u_{i}}{\partial x_{j}^{2}}+\frac{\partial^{2} u_{i}}{\partial x_{k}^{2}}\right), i=1,2,3
$$


where $u_{i}$ is the velocity component, respectively, in the $i, j$, and $k$ directions. The set of Equations (4) and (5) is averaged using the Reynolds decomposition which allows separating mean and fluctuating components of an instantaneous quantity. The Equations (6) and (7) are, indeed, the corresponding turbulence equations:

$$
\begin{gathered}
\frac{\partial \rho}{\partial t}+\frac{\partial\left(\rho u_{i}\right)}{\partial x}=0 \\
\frac{\partial\left(\rho u_{i}\right)}{\partial t}+\frac{\partial\left(\rho u_{i} u_{j}\right)}{\partial x_{j}}=-\frac{\partial p}{\partial x_{i}}+\frac{\partial}{\partial x_{j}}\left[\mu\left(\frac{\partial u_{i}}{\partial x_{j}}+\frac{\partial u_{j}}{\partial x_{i}}-\frac{2}{3} \delta_{i j} \frac{\partial u_{k}}{\partial x_{k}}\right)\right]+\frac{\partial}{\partial x_{j}}\left(-\rho \overline{u_{i}^{\prime} u_{j}^{\prime}}\right)
\end{gathered}
$$

This procedure generated additional unknowns that needed to be solved and required the turbulence model flow problem closure. The last term in Equation (7) is a second-order tensor, derivative with respect to $x_{j}$, it defines the turbulence effect, and it is known as the Reynolds stress. To determine the value of the Reynolds stress we used the $k-\varepsilon$ model, which has the following equation:

$$
\begin{gathered}
\frac{\partial(\rho k)}{\partial t}+\frac{\partial\left(\rho k u_{j}\right)}{\partial x_{j}}=\frac{\partial}{\partial x_{j}}\left[\left(\mu+\frac{\mu_{t}}{\sigma_{k}}\right) \frac{\partial k}{\partial x_{j}}\right]+G_{k}-\rho \varepsilon \\
\frac{\partial(\rho \varepsilon)}{\partial t}+\frac{\partial\left(\rho \varepsilon u_{j}\right)}{\partial x_{j}}=\frac{\partial}{\partial x_{j}}\left[\left(\mu+\frac{\mu_{t}}{\sigma_{\varepsilon}}\right) \frac{\partial \varepsilon}{\partial x_{j}}\right]+\rho c_{1} s_{\varepsilon}-\rho c_{2} \frac{\varepsilon^{2}}{k+\sqrt{v \varepsilon}}
\end{gathered}
$$

where $c_{1}=\max \left[0.43 \frac{\eta}{\eta+5}\right], \eta=s \frac{k}{\varepsilon}, s=\sqrt{2 s_{i j} s_{i j}}$ and where $G_{k}$ is the generation of kinetic energy of turbulence $k$ due to mean velocity gradients and $\mu_{t}$ represents the turbulent viscosity. The constant values typically used in $k-\varepsilon$ model are $c_{1 \varepsilon}=1.44, c_{2}=1.9, \sigma_{k}=1$, and $\sigma_{\varepsilon}=1.2$.

The set of Equations (6)-(9) consists of 6 equations that need to be discretized and solved in order to obtain a solution for the velocities and pressure. Ansys Fluent was used as a flow solver. To produce a reliable model to study the flow generated by the novel impellers, the simulation results were compared with the results presented in the literature for the Rushton turbine (RT). For the validation analysis, the same as in literature, flow and boundary conditions were used: Water as a working fluid with a viscosity of $\mu=0.001003 \mathrm{~kg} /(\mathrm{m} \cdot \mathrm{s})$ and a density of $\rho=998.2 \mathrm{~kg} / \mathrm{m}^{3}$. The vessel diameter was $D$ $=27 \mathrm{~cm}$, and equal to the height $H(D=H)$. The impeller was installed centrally, and a rotor diameter was $9.3 \mathrm{~cm}$. The impeller speed was considered as a parameter and the Reynolds number calculated from Equation (1) was in the range from $R e=1-100,000$.Computation algrid was tested for various resolutions, and the final resolution was the middle resolution which consisted of 190,000 control volumes (Figure 3).

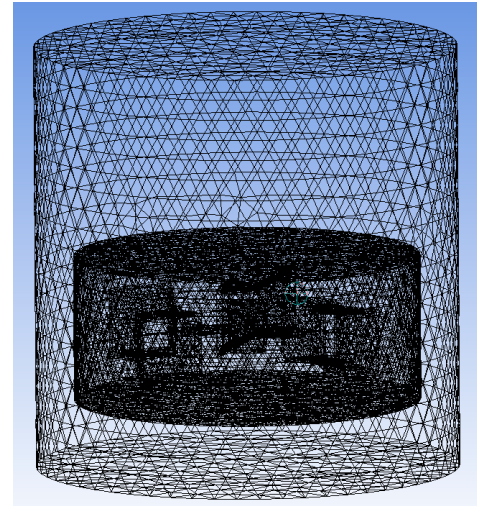

(a)

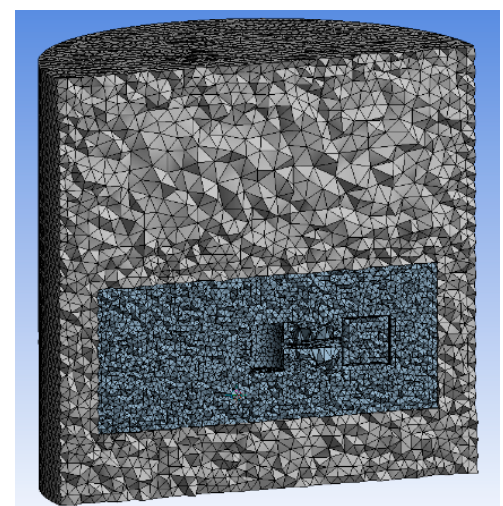

(b)

Figure 3. Mesh of the computational domain for Computational Fluid Dynamics (CFD) simulation global view (a) and inside the domain (b). 


\section{Results and Discussion}

\subsection{CFD Modelling}

The main goal for every industrial process related to the mixing is to find the most efficient way of mixing using as low power as possible and, at the same, maintaining the high quality of the product. Power required by the impeller is related to the power number $N_{p}$. Figure 4 shows the power number $N_{p}$, calculated for various Reynolds numbers in reference to the Rushton turbine and a new impeller (Novel-1). The results were also compared with the experimental data for the Rushton turbine available in the literature [10]. One can infer from this figure that the prediction for the Rushton turbine is compatible with CFD numerical results. The power number $N_{p}$ and Reynolds $\operatorname{Re}$ number were calculated according to Equation (1).

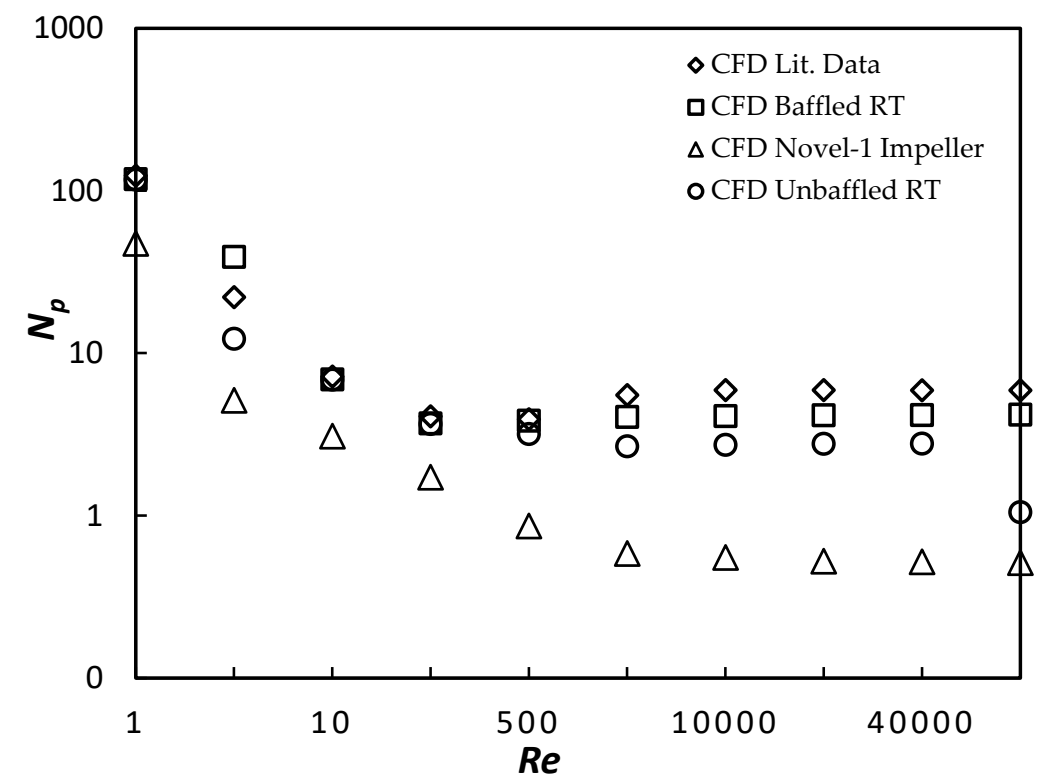

Figure 4. A comparison of power number $N_{p}$ of CFD predictions with literature data [10].

In reference to laminar, transient, and turbulent flow regimes, one may discern that power number $N_{p}$ at low Reynolds numbers depended on the Reynolds number and for the Novel-1 impeller was about 6-10 times lower than for the Rushton turbine. The power number $N_{p}$ for the turbulent flow regime remained constant. The power decrease for Novel-1 impeller was significant and applied to both laminar and turbulent flow regimes.

The lower power number $N_{p}$ for Novel-1 impeller denotes that the turbine required less energy. However, this parameter was not related to fluid mixing phenomena and the above-mentioned information is important but not sufficient to describe a new impeller as a device that represents higher efficiency. For that reason, it is worthwhile to keep track of the pumping capacity $Q$ parameter (see Equation (3)) which was directly related to the fluid motion and mixing phenomena. Figure 5 shows the normalized (by the factor $N d^{3}$ ) radial pumping capacity $Q_{r}$ for different Reynolds number through a cylindrical surface with a radius of $0.05 \mathrm{~m}$. As can be seen, the Novel-1 impeller yielded for a low Reynolds number, which was very promoted due to nondestructive mixing, a much higher value (up to 2.3 times) than for the Rushton turbine. However, for a Reynolds number above 750 (above the range important for very high viscous fluids mixing) evaluated pumping capacity $Q_{r}$ was lower for Novel-1 impeller than for the Rushton turbine. 


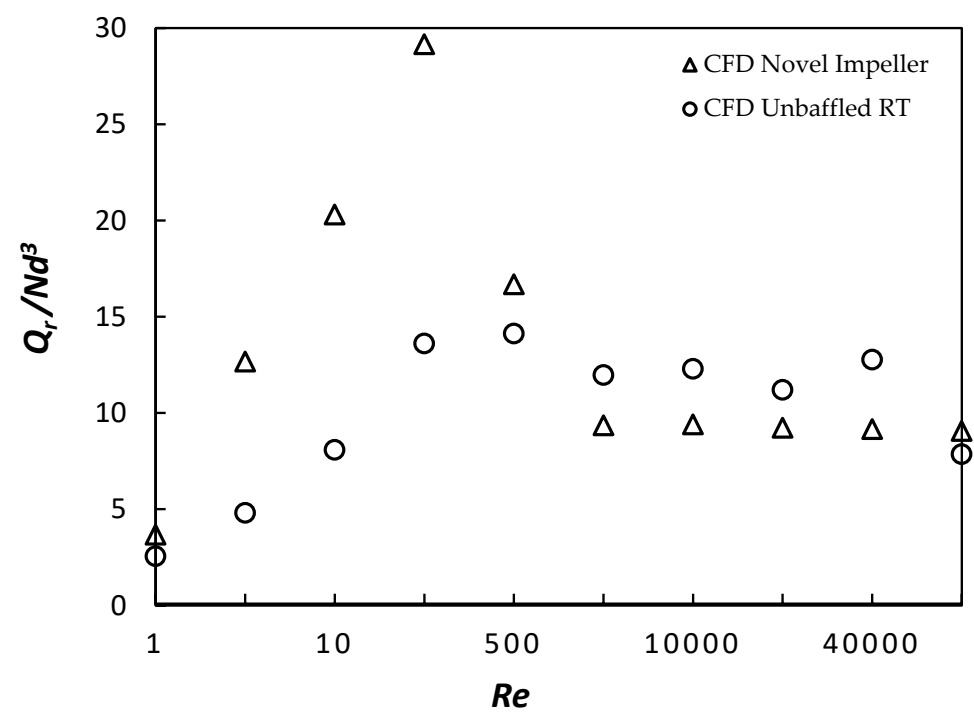

Figure 5. Normalized radial pumping capacity in the function of the Reynolds number.

After exceeding the value of $R e=500$, the dynamics of the increase in the amount of yield pumping capacity decreased. For the Novel-1 impeller, there was a strong relationship between Reynolds number $R e$ and power number $N_{p}$, and thus with the impeller pumping capacity such that with increasing Reynolds number Re decreased the power number $N_{p}$ and thereby the impeller pumping capacity increased up to the limit value equal to $R e=500$. Further increase of $R e$ caused a gradual reduction in the value of pumping capacity.

Figure 6 presents the mixing efficiency calculated as a ratio between the normalized pumping capacity and the power number for the Rushton turbine and Novel-1 impeller. One can infer from this figure a very high efficiency for the Novel-1 impeller for all fluid flow regimes analyzed in this work. The mixing efficiency for Novel-1 impeller increased very fast with the Reynolds number and for a higher value it remained constant. The high efficiency was related with the jet stream leaving the impeller which strongly interacted with the tank and generated a high energy dissipation next to and below the new impeller (compare with Figure 8). This showed that the Novel-1 impeller can be considered a very promising device for mixing for low as well as for high Reynolds numbers.

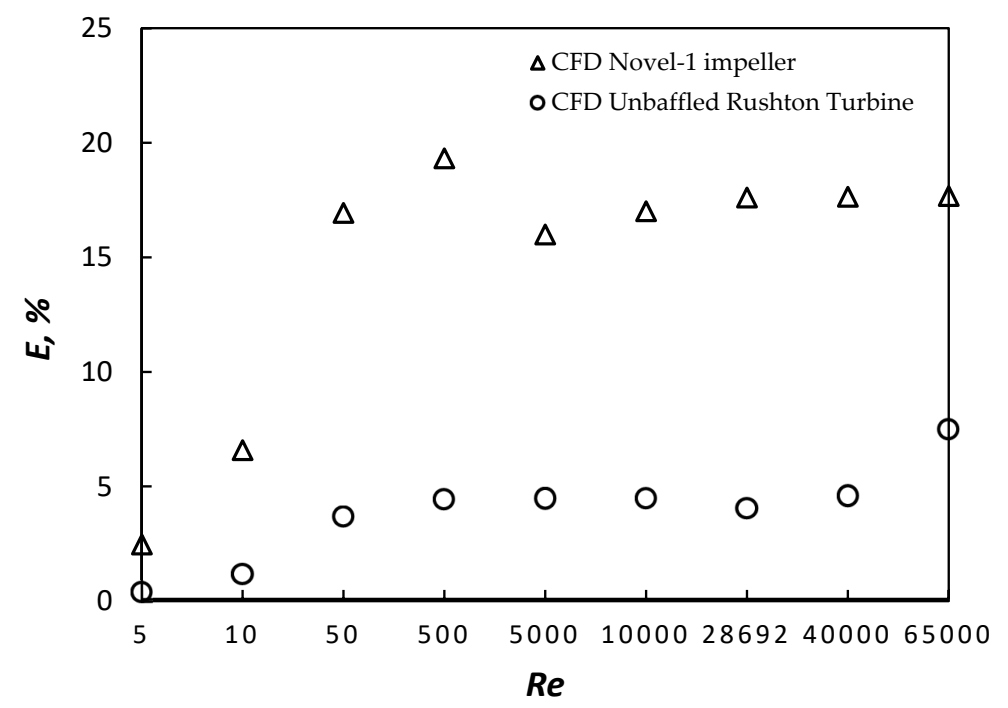

Figure 6. The efficiency comparison for Rushton turbine and Novel-1 impeller as a function of Reynolds number. 
Figure 7 shows the velocity vectors for Novel-1 impeller at rotational speed $N=200 \mathrm{rpm}$ $(R e=28,692)$ in an $x-y$ cross-section plane for the distance $z=7 \mathrm{~cm}$ from the vessel bottom and in $y-z$ cross-section plane for $\varphi=0^{\circ}$ and $180^{\circ}$. One may obtain from this figure a high-velocity magnitude in the internal part of the channel type blades of the impeller.

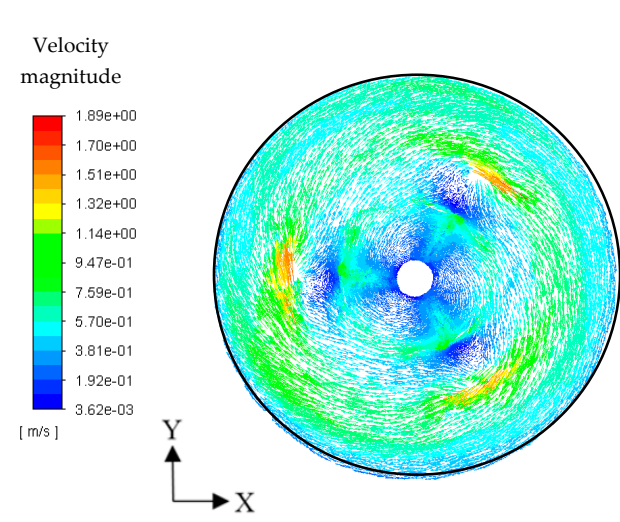

(a)

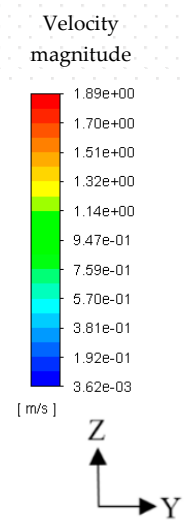

Y

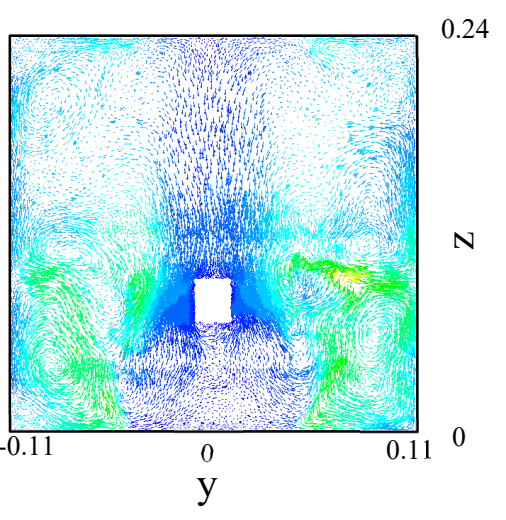

(b)

Figure 7. The velocity vectors in $x-y(\mathbf{a})$ and $y-z(\mathbf{b})$ cross-section plane for rotational speed at $R e=28,692$.

In Figure 8 the velocity vectors from the particle image velocimetry experimental measurements in the $y-z$ cross-section plane for $\varphi=0^{\circ}$ and two rotational speeds, $N=200(R e=28,692)$ and $400 \mathrm{rpm}$ $(R e=57,384)$ are presented for the Rushton turbine and the Novel-1 impeller. One may be observed as a high axial motion as well as a high radial one created by the Novel-1 impeller. In Figure $8 \mathrm{~d}$ a clear fluid "ejection" out the rotor zone towards the tank walls is seen. This is consistent with the numerical predictions and shows a very high mixing potential for the novel impeller. In reference to the fluid motion presented in Figure 8d, much lower velocities are observed in Figure 8b for Rushton turbine at the same Reynolds number. Apart from flow motion in the case of the Rushton turbine, the fluid was divided into two large co-rotating zones, one above and one below the impeller. Unfortunately, the fluid above and below impeller were not mixed with each other properly, which was the significant drawback of this configuration. This phenomenon was also seen at a lower rotational speed of $200 \mathrm{rpm}$ (at $R e=28,692$ ) presented in Figure 8a. One can infer from Figure 8c,d that the Novel-1 impeller was free from this drawback and fluid mixing occurred in the whole domain.
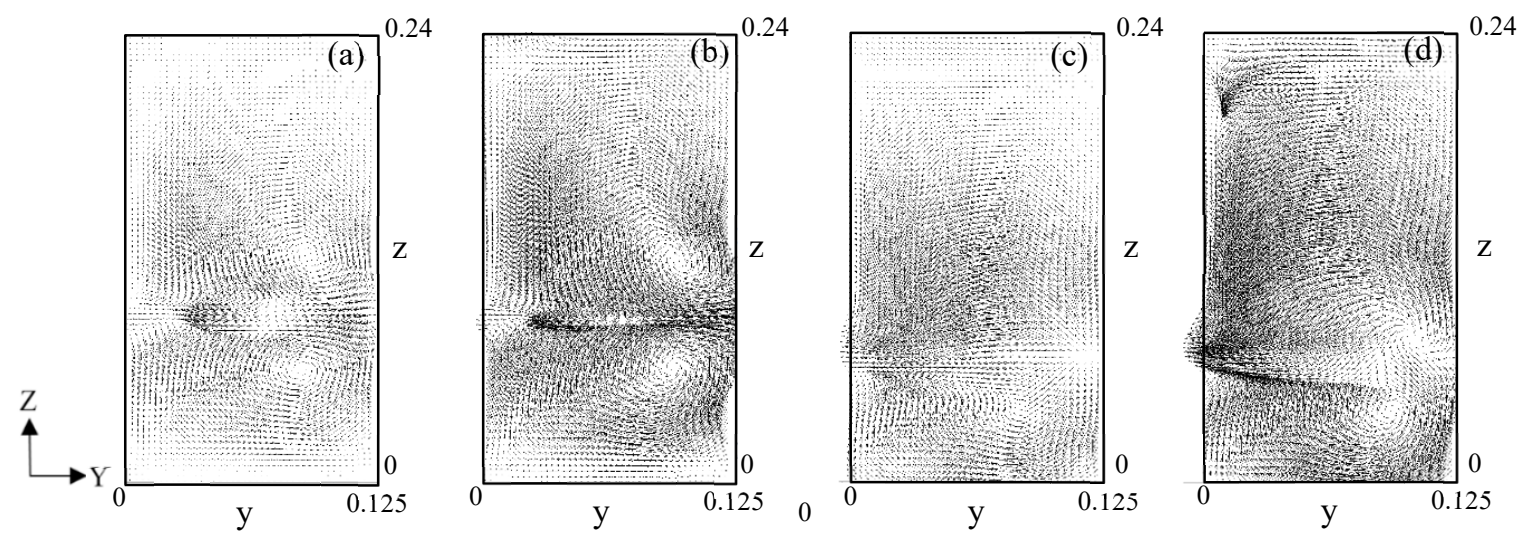

Figure 8. The velocity field from experimental measurement at $R e=28,692(\mathbf{a}, \mathbf{c})$ and at $\operatorname{Re}=57,384$ $(\mathbf{b}, \mathbf{d})$ for the Rushton turbine $(\mathbf{a}, \mathbf{b})$ and the Novel-1 impeller $(\mathbf{c}, \mathbf{d})$. 


\subsection{The Efficiency of Mixing Process}

The impeller which was analyzed in this work was equipped with a six-bladed Rushton turbine (case A) or the three-blade Novel impeller referred to as Novel-0 (case C). This innovative impeller was a rescaled copy of a new impeller type proposed for the industry.

Laboratory tests were carried out for the mechanically agitated vessel, in reference to the configuration presented in Figure 1. The dimensions which were used are shown in Table 2.

The series of measurements were performed for various distances of the impeller from the bottom of the tank $h$ and at a different rotational speed. The rotors for this analysis were placed at the heights of $h$ equal to $\frac{1}{4} H, 1 /{ }_{3} H$, and $\frac{1}{2} H$ of the fluid initial high $H$.

The impact of the vertical position of the impeller in the tank on the mixing efficiency was assessed. It was possible to compare the operation of Novel-0 impeller with reference to the Rushton turbine treated here as a reference impeller.

For the mixing efficiency analysis, all essential criteria numbers were evaluated: The power number $N_{p}$, the Reynolds number $R e$, as well as the pumping capacity $Q$ (or normalized pumping capacity) and finally the mixing efficiency $E$. The pumping capacity for the presented configuration was calculated for different Reynolds numbers through a horizontal surface (axial pumping capacity $Q_{z}$ ) and for the height $h$ equal to $1 \mathrm{~cm}$ above the vessel bottom. Pumping capacity was evaluated using the velocity obtained from the PIV measurement by integrating the mean axial velocity over the whole horizontal plane, i.e., from axis $r_{1}=0 \mathrm{~m}$ up to vessel wall $r_{2}=0.085 \mathrm{~m}$.

From the point of view of the industry, the most important parameter for assessing the mixing process is the power required by the impeller to generate fluid motion. This parameter was evaluated based on direct torque measurements.

The power number and the normalized pumping capacity $Q_{z}$ for the analyzed impellers are shown in Figures 9 and 10. The mean axial pumping capacity $Q_{z}$ through a horizontal surface located $1 \mathrm{~cm}$ above vessel bottom and dimensionalized by the $N \cdot d^{3}$ increased significantly with the Reynolds number. Values obtained from experimental measurements for the Novel-0 impeller were substantially higher in reference to the Rushton turbine. For the Reynolds number equal to 100, the difference was as high as one order of magnitude and increased with rotational speed. Therefore, the Novel-0 impeller for analogical rotational speed resulted in a remarkably higher flow motion which significantly enhanced the mixing process. That is the essential impeller advantage which is particularly important for the mixing process realization, for example, during the production of pharmaceuticals, where a technological process cannot be destructive or take a long time and rotational speed has to be low.

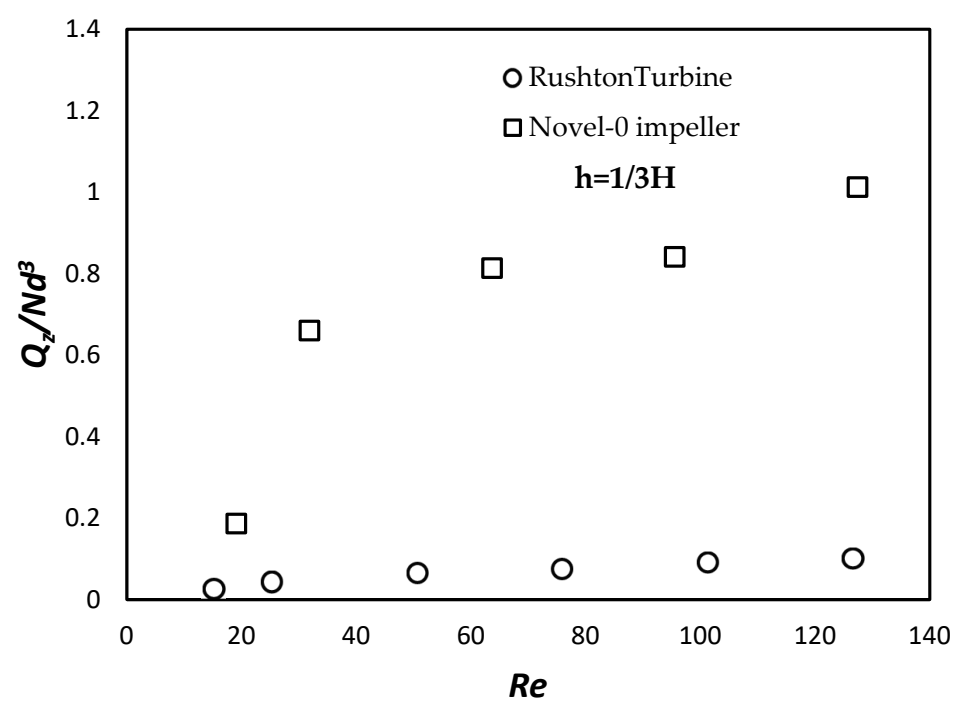

Figure 9. Normalized pumping capacity $Q_{z}$ evaluated from experimental measurements as a function of the Reynolds number and for $h=1 / 3 H$. 


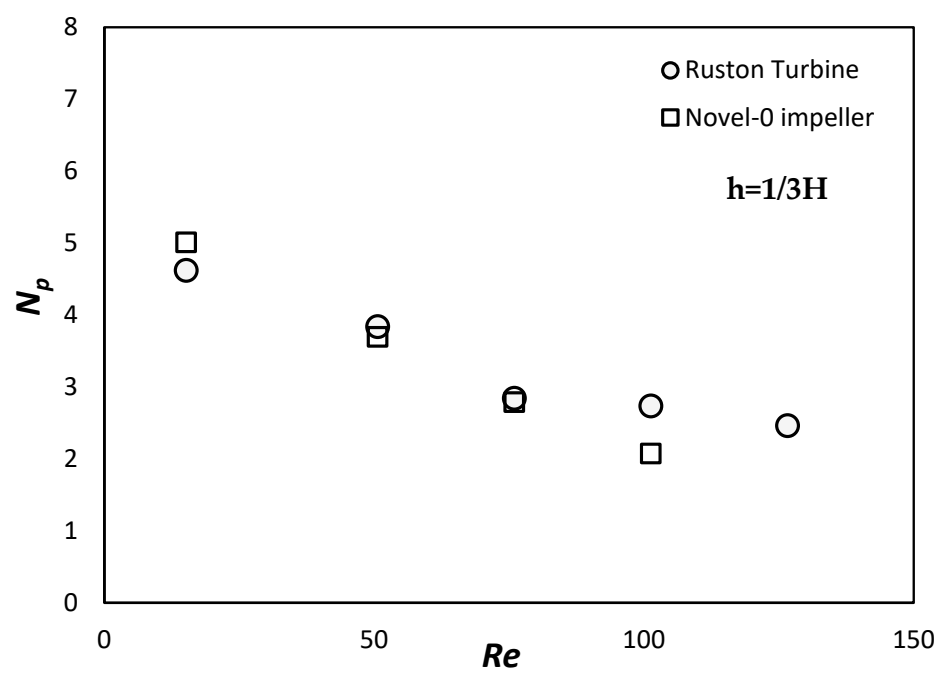

Figure 10. The power number $N_{p}$ obtained from experimental measurement as a function of the Reynolds number and for $h=1 / 3 H$.

Another important parameter which was directly related to the power required by the mixing process was the power number $N_{p}$. In Figure 10 this parameter is shown as a function of the Reynolds number. Results are presented for the Rushton turbine and the Novel-0 impeller at a constant distance above the vessel bottom equal to $1 / 3 \mathrm{H}(57 \mathrm{~mm})$. For other distances associated with impeller very similar results were obtained (in the trend of volatility). Based on experimental data, it was clearly seen that the power number $N_{p}$ depended on the Reynolds number. For a higher Reynolds number, a lower power number was observed. The power number $N_{p}$ for both impellers Novel- 0 and Rushton turbine showed a very similar value. Although the required power was very similar, the flow motion generated by the impellers was very different. This effect was observed for all impeller distances from the bottom of the tank that were analyzed in this work. When the power consumption required to mix the fluid decreased, at the same time the internal heat generation decreased and the mixing system required a smaller electrical motor, smaller gears, shaft, etc. All of these items minimize investment cost and operating cost.

The ratio of the $Q_{r} / N \cdot d^{3}$ to $N_{p}$, i.e., nondimensional pumping capacity to the nondimensional power, can be considered as a mixing efficiency parameter $E$.

This ratio for the Novel-0 impeller and for the Rushton turbine is presented in Figures 11 and 12, respectively, as a function of the Reynolds number and for various impeller distances from the bottom of the vessel. It can be seen that the mixing efficiency strongly depended on the Reynolds number and impeller distance $h$ from the tank bottom. For selected configurations, an almost 10-times greater efficiency for the Novel-0 impeller in reference to the Rushton turbine was observed. In Figures 11 and 12, the points represent the experimental data, while the individual lines represent a model fitting to all experimental results. For both the Rushton turbine and the Novel-0, impeller nonlinear semi-exponential functions were proposed as a best-fitting function. The empirical equation for mixing efficiency evaluation for Rushton turbine as a function of Reynolds number Re and normalized distance $h / H$ between impeller and vessel bottom can be presented as follows:

$$
E(R e, h)=0.08 \cdot R e \cdot(h / H)^{-1.15}
$$

where $H$ is the initial fluid height (under no agitation conditions) and $h$ is the distance between impeller and tank bottom. Coefficient of correlation $R^{2}$ for the Equation (10) is equal to 0.887 . 


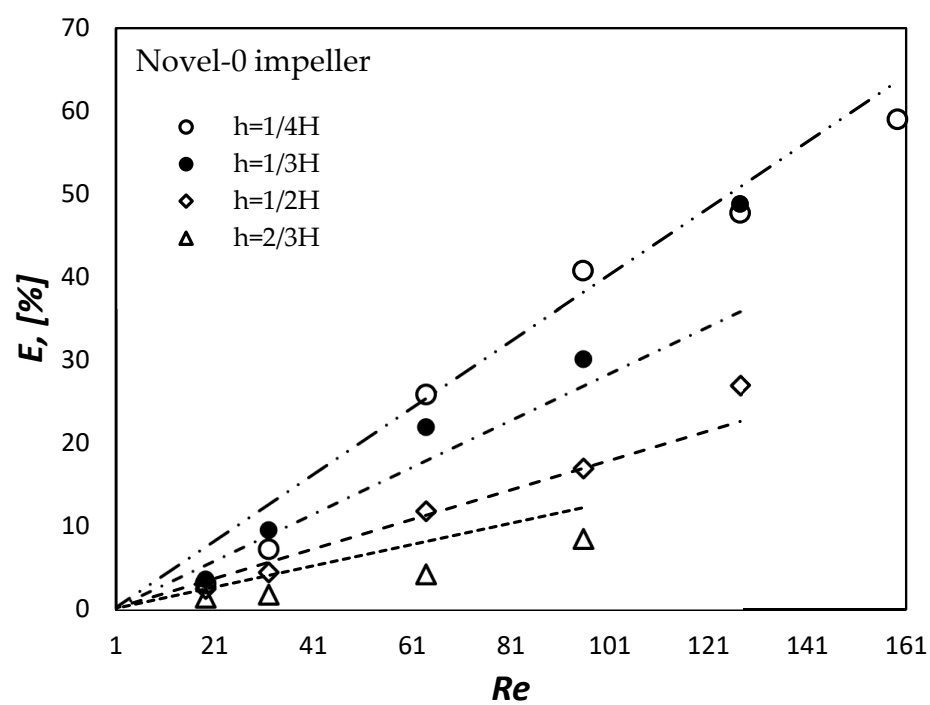

Figure 11. The mixing efficiency evaluated from experimental measurement for the Novel-0 impeller and different distances from the tank bottom.

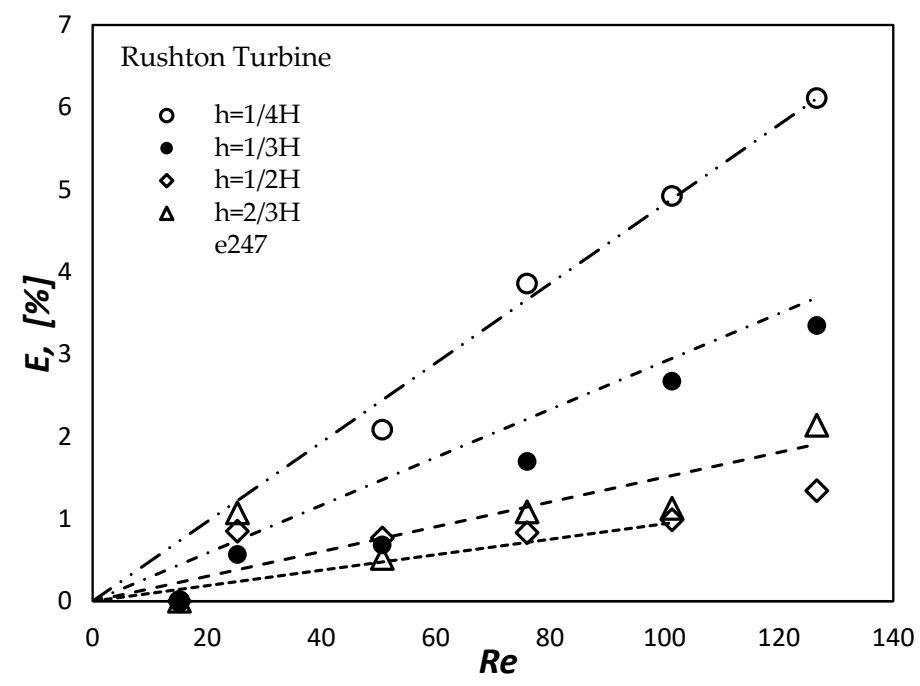

Figure 12. The mixing efficiency evaluated from experimental measurement for the Rushton turbine and different distances from the tank bottom.

A similar empirical equation for the mixing efficiency has been proposed for the Novel-0 impeller in the form as follows:

$$
E(R e, h)=0.0048 \cdot \operatorname{Re} \cdot(h / H)^{-1.65} .
$$

The coefficient of correlation $R^{2}$ for the Equation (11) is equal to 0.89. Equations (10) and (11) allow us to calculate mixing efficiency at any impeller height. One may discern that there is, for specified Reynolds number, an optimal impeller height which ensures the highest efficiency. Increasing impeller distance above or below this value results in mixing efficiency decrease. It can be observed that installing each of the impellers at a height equal to $2 / 3$ H and $1 / 2 \mathrm{H}$ caused similar and relatively low mixing efficiency. The most significant differences can be seen for impellers positions of $1 / 3 \mathrm{H}$ and $1 / 4$ $H$, respectively. At that range, dynamic increase in the value of $E$ was observed with the increase of $R e$. One should notice that the highest mixing efficiency which was observed in reference to the Rushton turbine and in reference to the Novel-0 impeller was $6.1 \%$ and $59.0 \%$, respectively, which demonstrated a huge potential as far as the improvement of the mixing process as well as the reduction of the energy consumption and operating cost are concerned. 


\subsection{The Power Number in Relation to the Impeller Geometry}

In order to evaluate the characteristic of impellers, a much larger Reynolds number range had to be implemented. In this section, an analysis of the experiments similar to those described above was performed but this time for Reynolds numbers whose value was up to 100,000 and using different fluids (100\% glycerol, $30 \%$ propylene glycol solution, and distilled water) all in the subcritical regime. The results obtained from the experimental measurement for the Rushton turbine and the Novel-0 impeller are presented in Figures 13 and 14.

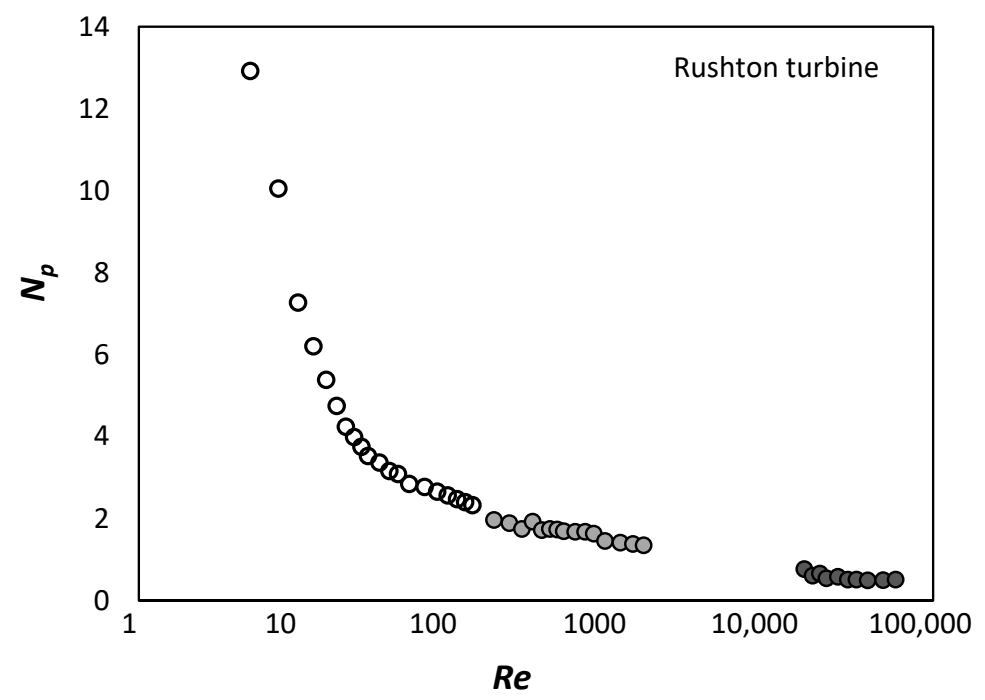

Figure 13. The power number $N_{p}$ evaluated from experimental measurements as a function of the Reynolds number for the Rushton turbine.

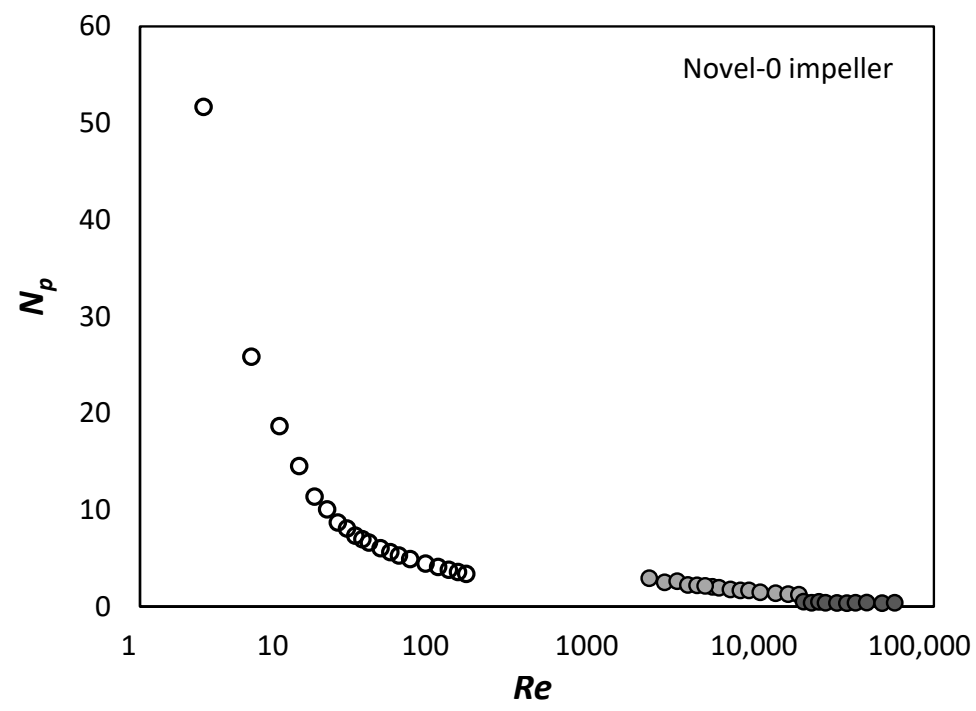

Figure 14. The power number $N_{p}$ evaluated from experimental measurements as a function of the Reynolds number for the Novel-0 impeller.

It is known from the literature that the setting angle of the Rushton turbine blades (here considered as a reference device) has a significant impact on the power number as well as the efficiency of the mixing process. The highest resistance (and, therefore, power consumption) occurred for angled blades (90 degrees), and the lowest for angles of 45 and 30 degrees [8]. This tendency was not even changed by the presence of baffles inside the vessel, although the authors measured for small values of the Reynolds number and classical positioning of the Rushton turbine blades (90 degrees), that the 
presence of baffles did not significantly affect the efficiency of mixing. Based on the experimental results for the Novel-0 impeller, it can be seen that for Re values above 1500 the "blade" angle of the impeller did not influence the value of the power number. Figure 15 shows that rotating the Novel impeller "blades" caused a decrease in the power number value, both when the blades were facing the top of the tank as well as when they were directed to the bottom of the tank.

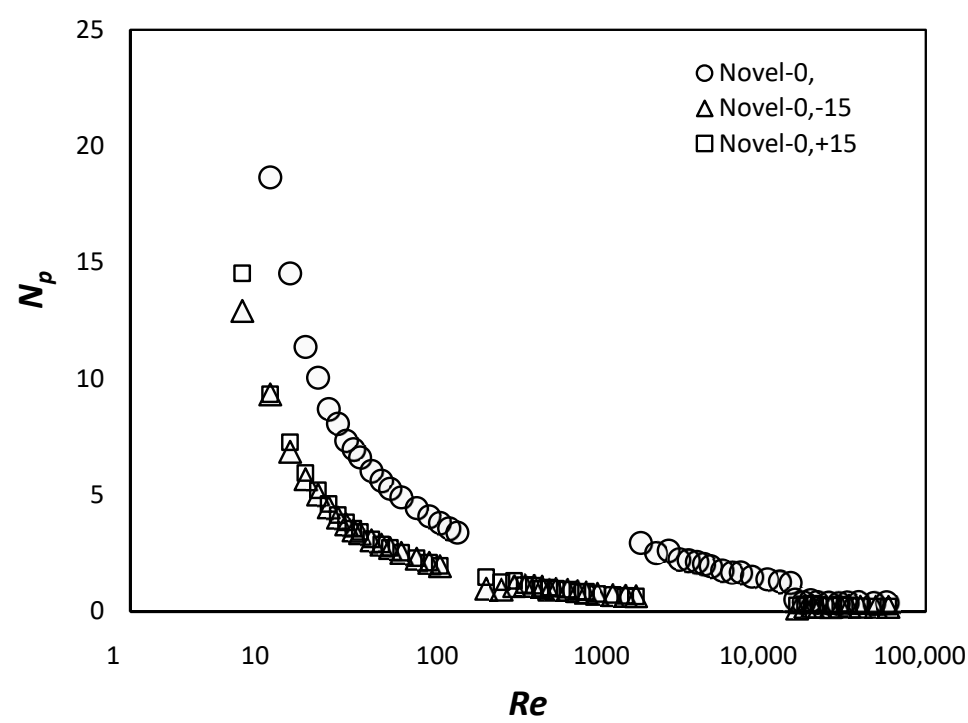

Figure 15. The power number $N_{p}$ from experimental measurements as a function of the Reynolds number for various angles of novel impeller "blades".

It should be noted that, according to calculations from the experiment measurements, rotating the blades of the Novel impeller by an angle of $+/-15$ degrees (bottom of the vessel) reduced power consumption, i.e., lower impeller resistance was observed for Reynolds number below 1000 .

\section{Conclusions}

The mixing process plays an essential role among a large number of chemical and industrial processes. The effectiveness of mixing depends on many parameters, but the most critical one is the impeller shape. This is also important in multiple-impeller systems. Independent of system and operation, the main goal has always been to find the most efficient way of mixing that could achieve a high-quality mixture usually with low axial velocity and low heat generation (which is a crucial issue for vitamins and enzymes and in cosmetics and food production) and using as low power as possible. Undeniably, the energy consumption during the mixing process can be significantly minimized improving the shape of the impeller. When the power required to carry out the process decreased, at the same time the internal heat generation decreased and the mixing system required a smaller electrical motor, smaller gears, shaft, etc. All of these items minimize investment cost and operating cost.

Using a new impeller shape presented in this work, it is possible to significantly reduce the power consumption while maintaining at the same time a similar or better level of mixing. It was found that power number for the reference Rushton turbine was much higher in comparison to optimized Novel impellers. The results evaluated from experimental measurements and numerical calculations showed that at least 6-10 times lower energy consumption can be obtained. The new geometry of the impeller that is currently being developed is a promising alternative to the classic rotating disc or other blades- and nonblades-based impeller types. With this solution, it is also possible to reduce the power number $N_{p}$ for a low as well a high Reynolds number, i.e., for laminar or turbulent flow regime. After exceeding the Reynolds number (about $R e=1000$ ), which is critical for the phenomena, a turbulent regime occurred and stabilization of the power number was observed. 
The calculated mean axial pumping capacity $Q_{z}$ through a horizontal surface located $1 \mathrm{~cm}$ above the bottom of the vessel was significantly higher for Novel-0 impeller in reference to the Rushton turbine. For the Reynolds number whose value was about 100, the difference was as high as one order of magnitude and it increased further with rotational speed. Those are the essential impeller advantages particularly for the realization of the mixing process during the production of pharmaceuticals or cosmetics, where a technological process cannot be destructive, where it can take a very long time, and when the rotational speed cannot be very high.

The ratio $Q_{r} / N \cdot d^{3}$ to the $N_{p}$, i.e., nondimensional pumping capacity to the nondimensional power, can be considered a mixing efficiency parameter $E$. This ratio for selected cases presented here was 10 times higher for novel impeller than for the Rushton turbine. However, results that were provided showed also that the mixing efficiency was significantly influenced by the distance between the impeller and the vessel bottom and, generally speaking, the impeller-to-fluid configuration. It means that impeller shape should be optimized in parallel with vessel shape or at least for predetermined geometrical configuration of the vessel.

Author Contributions: Conceptualization and measurements, M.J. and A.M.; methodology and software, M.J. and L.D.; supervision, M.J.; writing original draft and review and editing, M.J. and A.M. All authors have read and agreed to the published version of the manuscript.

Funding: The present work was supported by the Polish Ministry of Science (Grant MNiSW/2019/162/DIR).

Conflicts of Interest: The authors declare no conflict of interest.

\section{Nomenclature}

$H \quad$ Water height in the tank, $\mathrm{m}$

$H_{\mathrm{c}} \quad$ Tank total height, $\mathrm{m}$

$h \quad$ Height of the impeller, $\mathrm{m}$

D Diameter of the tank, $\mathrm{m}$

d Diameter of the impeller, $\mathrm{m}$

$a \quad$ Height of the impeller section, $\mathrm{m}$

$b \quad$ Width of the impeller section, $\mathrm{m}$

c Thickness for Rushton turbine blades, $\mathrm{m}$

$l \quad$ Length of the impeller, $\mathrm{m}$

$d_{1}, d_{2} \quad$ Diameter at inlet, outlet in Novel-0 impeller, $\mathrm{m}$

$w \quad$ Width of the impeller, $\mathrm{m}$

$v \quad$ Velocity components, $\mathrm{m} / \mathrm{s}$

$p \quad$ Pressure, $\mathrm{kg} /\left(\mathrm{m} \cdot \mathrm{s}^{2}\right)$

$N_{p} \quad$ Power number $=\frac{P}{\rho N^{3} D^{5}}$

P Power, $\mathrm{W}$

$N \quad$ Impeller rotational speed, rps

$\rho \quad$ Fluid density, $\mathrm{kg} / \mathrm{m}^{3}$

$\mu \quad$ Fluid viscosity, $\mathrm{kg} /(\mathrm{m} \cdot \mathrm{s})$

$\tau \quad$ Torque, $\mathrm{N} \cdot \mathrm{m}$

\section{References}

1. Jaszczur, M.; Młynarczykowska, A.; Hanus, R. An analysis of the velocity field distribution inside the flotation chamber. J. Phys. Conf. Ser. 2016, 745, 032121. [CrossRef]

2. Scargiali, F.; Busciglio, A.; Grisafi, F.; Tamburini, A.; Micale, G. Power consumption in uncovered unbaffled stirred tanks: Influence of viscosity and flow regime. Ind. Eng. Chem. Res. 2013, 52, 14998-15005. [CrossRef]

3. Su, T.; Yang, F.; Li, M.; Wu, K. Characterization of the hydrodynamics of a covering plate Rushton impeller. Chin. J. Chem. Eng. 2017, 26, 1392-1400. [CrossRef]

4. Scargiali, F.; Tamburini, A.; Caputo, G.; Micale, G. On the assessment of power consumption and critical impeller speed in vortexing unbaffled stirred tanks. Chem. Eng. Res. Des. 2017, 132, 99-110. [CrossRef] 
5. Kumaresan, T.; Jyeshtharaj, J.B. Effect of impeller design on the flow pattern and mixing in stirred tanks. Chem. Eng. J. 2005, 115, 173-193. [CrossRef]

6. Basavarajappa, M.; Draper, T.; Toth, P.; Ring, T.A.; Miskovic, S. Numerical and experimental investigation of single phase flow characteristics in stirred tanks using Rushton turbine and flotation impeller. Miner. Eng. 2015, 83, 156-167. [CrossRef]

7. Ameur, H.; Kamla, Y.; Sahel, D. Optimization of the Operating and Design Conditions to Reduce the Power Consumption in a Vessel Stirred by a Paddle Impeller. Per. Pol. Mech. Eng. 2018, 62, 312-319. [CrossRef]

8. Major-Godlewska, M.; Karcz, J. Power consumption for an agitated vessel equipped with pitched blade turbine and short baffles. Chem. Zvesti. 2018, 72, 1081-1088. [CrossRef] [PubMed]

9. Karcz, J.; Mackiewicz, B. Effects of vessel baffling on the drawdown of floating solids. Chem. Pap. 2009, 63, 64-171. [CrossRef]

10. Rushton, J.H.; Costich, E.W.; Everett, H.J. Power characteristics of mixing impellers Part II. Chem. Eng. Prog. 1950, 46, 467-476.

11. Furukawa, H.; Kato, Y.; Inoue, Y.; Kato, T.; Hashimoto, S. Correlation of Power Consumption for Several Kinds of Mixing Impellers. Int. J. Chem. Eng. 2012, 2012, 106496. [CrossRef]

12. Ferrari, S.; Rossi, L. Particle tracking velocimetry and accelerometry (PTVA) measurements applied to quasi-two-dimensional multi-scale flows. Exp. Fluids 2008, 44, 876-886. [CrossRef]

13. Rossi, L.; Bocquet, S.; Ferrari, S.; de la Garcia Cruz, J.M.; Lardeau, J.M.S. Control of flow geometry using electromagnetic body forcing. Int. J. Heat Fluid Flow 2009, 30, 505-513. [CrossRef]

14. Delafosse, A.; Line, A.; Morchain, J.; Guiraud, P. LES and URANS simulations of hydrodynamics in mixing tank: Comparison to PIV experiments. Chem. Eng. Res. Des. 2008, 86, 1322-1330. [CrossRef]

15. Delafosse, A.; Collignon, M.L.; Calvo, S.; Delvign, F.; Crine, M.; Thonart, P.; Toye, D. CFD-based compartment model for description of mixing in bioreactors. Chem. Eng. 2013, 106, 76-85. [CrossRef]

16. Singh, H.; Fletcher, D.F.; Nijdam, J.J. An assessment of different turbulence models for predicting flow in a baffled tank stirred with a Rushton turbine. Chem. Eng. Sci. 2011, 66, 5976-5988. [CrossRef]

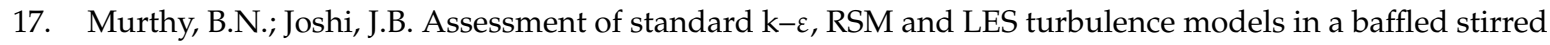
vessel agitated by various impellers. Chem. Eng. Sci. 2008, 63, 5462-5495. [CrossRef]

18. Alliet-Gaubert, R.; Sardeing, R.; Xuereb, C.; Hobbes, P.; Letellier, B.; Swaels, P. CFD analysis of industrial multi-staged stirred vessels. Chem. Eng. Process. 2006, 45, 415-427. [CrossRef]

19. Gogate, R.; Beenackers, A.A.; Pandit, A.B. Multiple-impeller systems with a special emphasis on bioreactors: A critical review. Biochem. Eng. 2002, 6, 109-144.

20. Liu, B.; Zhang, Y.; Chen, Y.; Li, P.; Jin, Z. Power consumption and flow field characteristics of a coaxial mixer with a double inner impeller. Chin. J. Chem. Eng. 2015, 23, 1-6. [CrossRef]

21. Kazemzadeh, A.; Ein-Mozaffari, F.; Lohi, A.; Pakzad, L. Intensification of mixing of shear-thinning fluids possessing yield stress with the coaxial mixers composed of two different central impellers and an anchor. Chem. Eng. Process Process Intensif. 2017, 111, 101-114.

22. Letellier, B.; Xuereb, C.; Swaels, P.; Hobbes, P.; Bertrand, J. Scale-up in laminar and transient regimes of a multi-stage stirrer, a CFD approach. Chem. Eng. Sci. 2002, 57, 4617-4632. [CrossRef]

23. You, A.; Raman, A.A.; Shah, R.; Nor, M.I.M. Multiple-impeller stirred vessel studies. Chem. Eng. 2014, 30, 323-336. [CrossRef]

24. Bliem, V.; Schultz, H.J. Investigation of Horizontal Velocity Fields in Stirred Vessels with Helical Coils by PIV. Int. J. Chem. Eng. 2014, 2014, 763473. [CrossRef]

25. Jaehrling, K.; Schultz, H.J. Flow Fields in Stirred Vessels Depending on Different Internal Heat Exchangers and Vessel Bottoms. Chem. Ing. Tech. 2019, 91, 1281-1292. [CrossRef]

26. Stefan, A.; Schultz, H.J. Use of OpenFOAM for the Investigation of Mixing Time in Agitated Vessels with Immersed Helical Coils; Nóbrega, J., Jasak, H., Eds.; Springer: Cham, Switzerland, 2019.

27. Busciglio, F.; Scargiali, F.; Grisafib, F.; Brucatob, A. Oscillation dynamics of free vortex surface in uncovered unbaffled stirred vessels. Chem. Eng. J. 2016, 285, 477-486. [CrossRef]

28. Scargiali, F.; Busciglio, A.; Grisafi, F.; Brucato, A. Mass transfer and hydrodynamic characteristics of unbaffled stirred bio-reactors: Influence of impeller design. Biochem. Eng. J. 2014, 82, 41-47. [CrossRef]

29. Scargiali, F.; Busciglio, A.; Grisafi, F.; Brucato, A. Free surface oxygen transfer in large aspect ratio unbaffled bio-reactors, with or without draft tube. Biochem. Eng. J. 2015, 100, 16-22. [CrossRef] 
30. Wu, J.; Wang, S.; Nguyen, B.; Marjavaara, D.; Eriksson, O. Improved mixing in a magnetite iron ore tank via swirl flow: Lab-scale and full-scale studies. Chem. Eng. Technol. 2016, 39, 505-514. [CrossRef]

31. Alvarez, M.M.; Zalc, J.M.; Shinbrot, T.; Arratia, P.; Muzzio, J. Mechanisms of Mixing and Creation of Structure in Laminar Stirred Tanks. AIChE J. 2002, 48, 2135-2148. [CrossRef]

(C) 2020 by the authors. Licensee MDPI, Basel, Switzerland. This article is an open access article distributed under the terms and conditions of the Creative Commons Attribution (CC BY) license (http://creativecommons.org/licenses/by/4.0/). 